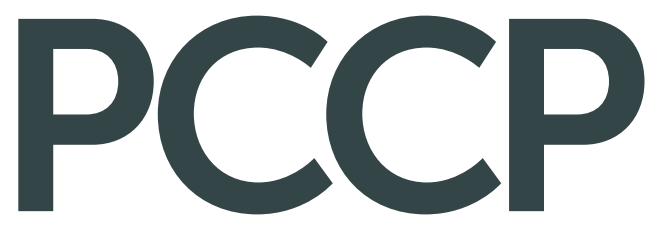

Physical Chemistry Chemical Physics www.rsc.org/pccp

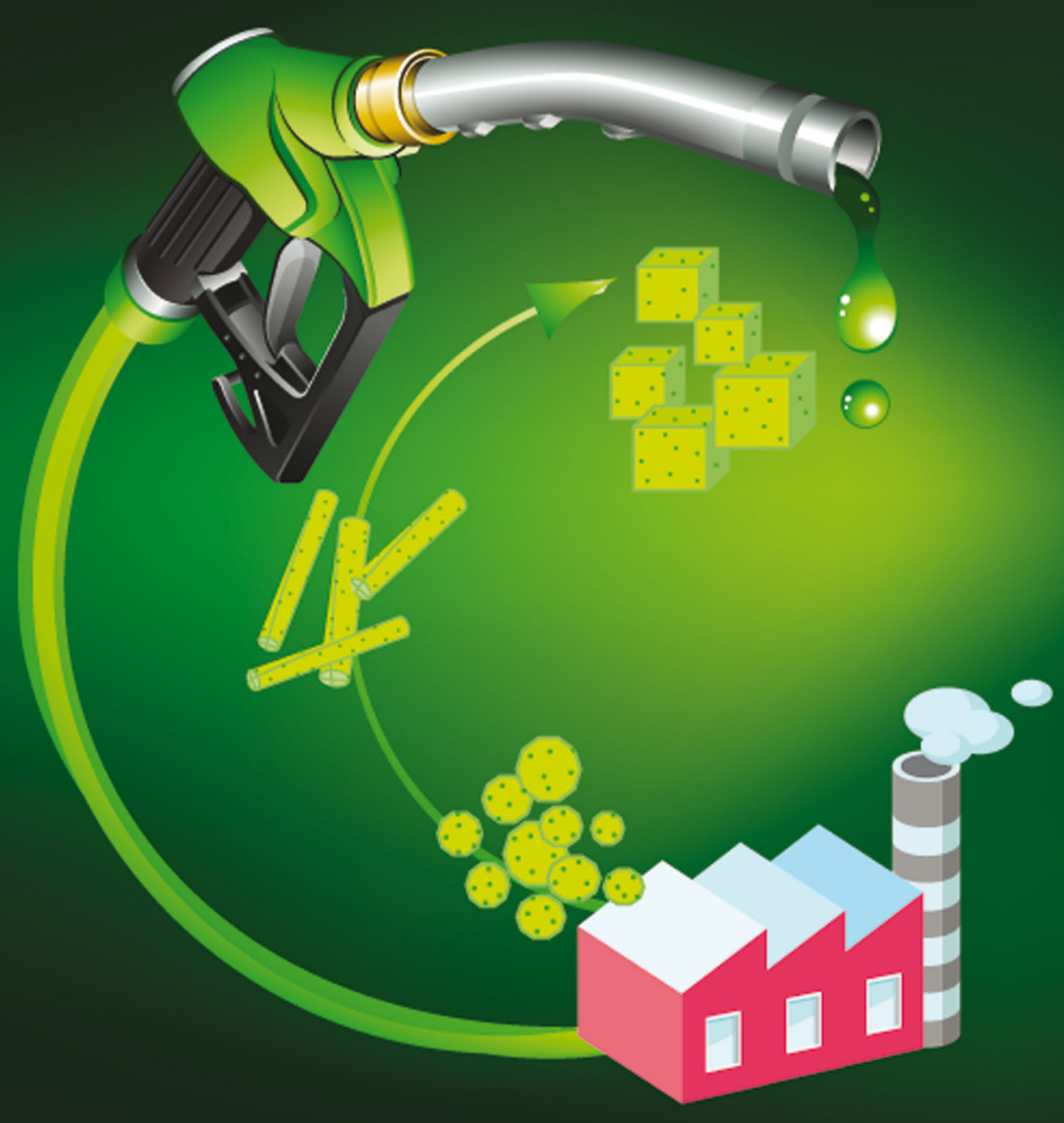

ISSN 1463-9076

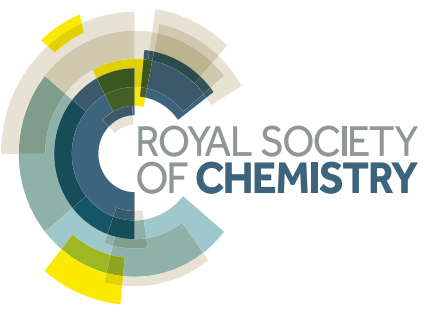

\title{
COMMUNICATION
}

Laura Torrente-Murciano et al.

Effect of nanostructured ceria as support for the iron catalysed

hydrogenation of $\mathrm{CO}_{2}$ into hydrocarbons 


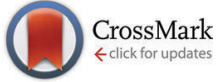

Cite this: Phys. Chem. Chem. Phys., 2016, 18, 15496

Received 16th December 2015, Accepted 27th January 2016

DOI: $10.1039 / c 5 c p 07788 e$

www.rsc.org/pccp

\section{Effect of nanostructured ceria as support for the iron catalysed hydrogenation of $\mathrm{CO}_{2}$ into hydrocarbons}

\author{
Laura Torrente-Murciano, ${ }^{\star a b}$ Robert S. L. Chapman, ${ }^{\text {bc }}$ Ana Narvaez-Dinamarca, ${ }^{\text {bd }}$ \\ Davide Mattia $^{\mathrm{b}}$ and Matthew D. Jones ${ }^{\mathrm{e}}$
}

\begin{abstract}
This paper demonstrates the key role of the property-structure relationship of the support on iron/ceria catalysts on the hydrocarbon selectivity and olefin-to-paraffin ratio for the direct hydrogenation of carbon dioxide into hydrocarbons. The effect is directly related to the reducibility of the different nanostructured ceria supports and their interaction with the iron particles. Herein, we demonstrate that the iron-based catalysts can be modified not only by the addition of promoters, commonly reported in the literature, but also by careful control of the morphology of the ceria support.
\end{abstract}

The environmental impact of a continuous release of $\mathrm{CO}_{2}$ into the atmosphere is urging the scientific community to find novel ways of converting $\mathrm{CO}_{2}$ waste into valuable chemicals. ${ }^{1,2}$ Implementation of oxyfuel combustion on power stations produces highly concentrated (>98\%) $\mathrm{CO}_{2}$ streams for carbon capture and storage (CCS). Alternatively, these waste streams can be used as chemical feedstock overcoming the dilution problems associated to the recovery of $\mathrm{CO}_{2}$ from the atmosphere. ${ }^{3,4}$ The last decades have witnessed a plethora of studies to unlock the potential of carbon dioxide as a raw material in the synthesis of carboxylates, carbonates, carbamates, C-1 molecules such as formic acid and methanol as well as fuels. ${ }^{2,5,6}$ Amongst them, hydrogenation of $\mathrm{CO}_{2}$ either through the methanol ${ }^{7,8}$ or the non-methanol ${ }^{5,9}$ mediated routes is a promising and flexible pathway for the production of commodity chemicals such as methanol, methane, and $\mathrm{C}_{2+}$ hydrocarbons (HCs) currently produced from petroleum-based sources. Specifically, the non-methanol mediated tandem system conversion of $\mathrm{CO}_{2}$ into a more reactive $\mathrm{CO}$ moiety via reverse water gas shift reaction (RWGS) followed by conventional Fischer-Tropsch (F-T) for the formation of hydrocarbons is an attractive and highly prized route for fuel production. ${ }^{10}$

\footnotetext{
${ }^{a}$ Department of Chemical Engineering and Biotechnology, University of Cambridge, Cambridge, CB2 3RA, UK. E-mail: lt416@cam.ac.uk

${ }^{b}$ Department of Chemical Engineering, University of Bath, Bath, BA2 7AY, UK

${ }^{c}$ Centre for Sustainable Chemical Technologies, University of Bath, Bath, UK

${ }^{d}$ Department of Environmental Engineering and Natural Resources,

Universidad Católica de la Santísima Concepción, Concepción, Chile

${ }^{e}$ Department of Chemistry, University of Bath, Bath, BA2 7AY, UK
}

In this case, cobalt and iron based catalysts are the most studied systems. ${ }^{11}$ The former, widely used in Fischer-Tropsch synthesis, highly increases its methanation ability when the feed is shifted from syngas to a $\mathrm{CO}_{2} / \mathrm{H}_{2}$ mixture. ${ }^{12-14}$ On the other hand, ironbased catalysts are attractive due to the olefinic hydrocarbons formed during $\mathrm{F}-\mathrm{T},{ }^{15}$ although their RWGS activity is considerably lower than the cobalt-based systems. In any case, the initial iron phases for the reduced fresh catalyst, mainly $\alpha-\mathrm{Fe}$ and $\mathrm{Fe}_{3} \mathrm{O}_{4}$ are believed to be transformed under reaction conditions into an amorphous, and probably oxide, iron phase, active for the RWGS reaction. ${ }^{5}$ Additionally, recent studies have confirmed that iron carbide species, ${ }^{16}$ and in particular $\mathrm{Fe}_{5} \mathrm{C}_{2}$, act as active sites for the production of olefins and long hydrocarbons $\left(\mathrm{C}_{5}^{+}\right)$in the hydrogenation of CO via the Fischer-Tropsch process. ${ }^{17-19}$ As iron-only catalysts tend to have high selectivities towards methane, a great effort has been focused on the use of promoters to enhance hydrocarbon formation. Metal alkali ions such as $\mathrm{Na}^{+}, \mathrm{K}^{+}$or $\mathrm{Cs}^{+}$ decrease the hydrogenation ability of the iron active sites, decreasing the selectivity to methane and lower paraffins while also increasing the conversion of $\mathrm{CO}_{2}$ and the chain-growth probability. ${ }^{20}$ In particular, $\mathrm{K}^{+}$favours the re-oxidation of $\mathrm{Fe}$ during the reaction. ${ }^{21}$ The addition of manganese acts not only as an electronic modifier but also as a structural promoter with similar effects. $^{22,23}$ Less attention has been paid to the effect of the support on the $\mathrm{CO}_{2}$ hydrogenation reactivity although scattered screening studies demonstrate that it can have a clear effect not only in the activity but also in the selectivity. ${ }^{20}$ The effect of the support morphology on the activity and selectivity has been previously demonstrated for other systems such as $\mathrm{WGS}^{24}$ or oxidation reactions. ${ }^{25,26}$ Specifically, a considerable catalyst development in the last years has been based on the effect of nanostructuring of ceria in its reducibility ${ }^{27}$ and its interaction with metal nanoparticles. ${ }^{28}$ This paper presents for the first time the effect of the morphology of the support at the nano-scale of iron/ceria catalysts on the resulting activity to provide insights of the role of the metalsupport interaction on the $\mathrm{CO}_{2}$ hydrogenation system.

A series of nanostructured ceria materials were synthesised using a hydrothermal method. The morphology at the nanoscale 
Table 1 Catalytic performance of 20 wt\% Fe supported on nanostructured ceria for the hydrogenation of $\mathrm{CO}_{2}$

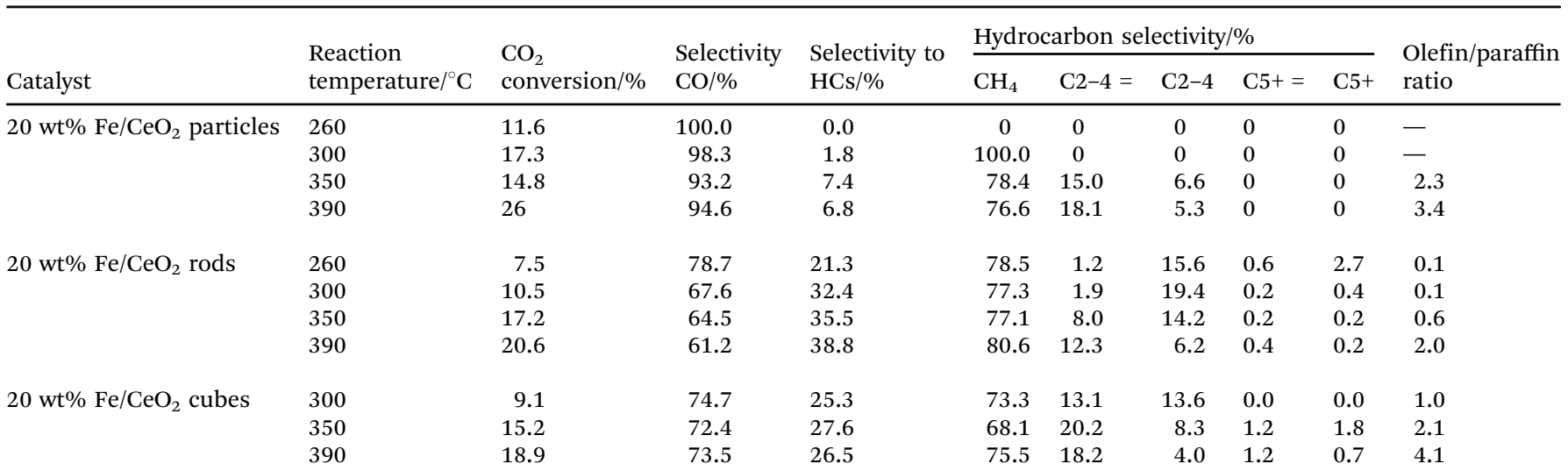

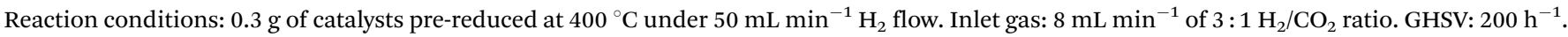
The experimental error associated to the analysis is $<4 \%$.

is modified by varying the synthetic conditions. ${ }^{25}$ Pure ceria nanoparticles $(\sim 5 \mathrm{~nm})$ are formed at a $\mathrm{NaOH}$ concentration of $5 \mathrm{M}$ at $70{ }^{\circ} \mathrm{C}$. Increasing the base concentration to $10 \mathrm{M}$ and the temperature $\left(100{ }^{\circ} \mathrm{C}\right)$ leads to ceria rods with an average diameter of $7 \mathrm{~nm}$ and assorted lengths between $20-80 \mathrm{~nm}$. Ceria cubes with sizes between $20-100 \mathrm{~nm}$ were synthesised at $180{ }^{\circ} \mathrm{C}$ in a base concentration of $15 \mathrm{M}$. Full characterisation can be found elsewhere. ${ }^{25}$

Iron was supported by incipient wetness impregnation using $\mathrm{Fe}\left(\mathrm{NO}_{3}\right)_{3} \cdot 9 \mathrm{H}_{2} \mathrm{O}$ as the precursor. The resulting catalysts were in situ pre-reduced at $400{ }^{\circ} \mathrm{C}$ under a hydrogen flow prior to being tested in the $\mathrm{CO}_{2}$ hydrogenation reaction at different temperatures (Table 1). Fig. 1 shows representative TEM pictures of the different $\mathrm{Fe} / \mathrm{CeO}_{2}$ catalysts. It can be observed that the support morphology is maintained after the iron impregnation and reduction. Nanoparticulated ceria present dimension between $5-15 \mathrm{~nm}$, ceria rods have diameters between $5-15 \mathrm{~nm}$ with assorted lengths and ceria nanocubes have dimensions between $40-100 \mathrm{~nm}$. Size distributions of the bare ceria support can be found in our previous studies. ${ }^{26}$ In all cases, iron nanoparticles are not easily identified due to the similarity of contrast with the ceria. $\dagger$

The catalysts were tested in the direct hydrogenation of carbon dioxide into hydrocarbons under different reaction conditions (Table 1). All $20 \mathrm{wt} \%$ Fe nanostructured catalysts present comparable $\mathrm{CO}_{2}$ conversions which increase as the reaction temperature increases. However, considerable differences are observed in the hydrocarbon (HC) and $\mathrm{CO}$ selectivities. Fe supported on ceria particles presents much lower hydrocarbon formation than the other two catalysts, being the Fe/ceria rods the catalyst with higher hydrocarbon conversion for a given reaction temperature.

In addition, similar methane selectivities (70-80\%) versus longer $\mathrm{HC}$ are observed in all the catalytic systems with the exception of the $\mathrm{Fe} /$ ceria particles that only produce methane at temperatures below $350{ }^{\circ} \mathrm{C}$. Iron-only catalysts in the absence of promoters such as $\mathrm{K}, \mathrm{Mn}$, etc. are known to produce $\mathrm{CH}_{4}$ as main product $^{29}$ in a similar catalytic pathway that occurs during natural gas formation in coalbeds producing a natural gas composition with $>90 \%$ methane. ${ }^{30}$ In this study, we have intentionally avoided the addition of any modifier to understand the role of the morphology of nanostructured ceria support on the iron active species and their resulting reactivities.

As the reaction temperature increases, the HC selectivity of the $\mathrm{Fe} /$ ceria rods catalyst greatly increases up to $350{ }^{\circ} \mathrm{C}$ compared to the ceria cubes counterpart whose HC selectivity is almost independent on temperature. Indeed, the apparent activation energy of the Fe/ceria cubes is considerable lower $\left(30.2 \mathrm{~kJ} \mathrm{~mol}^{-1}\right)$
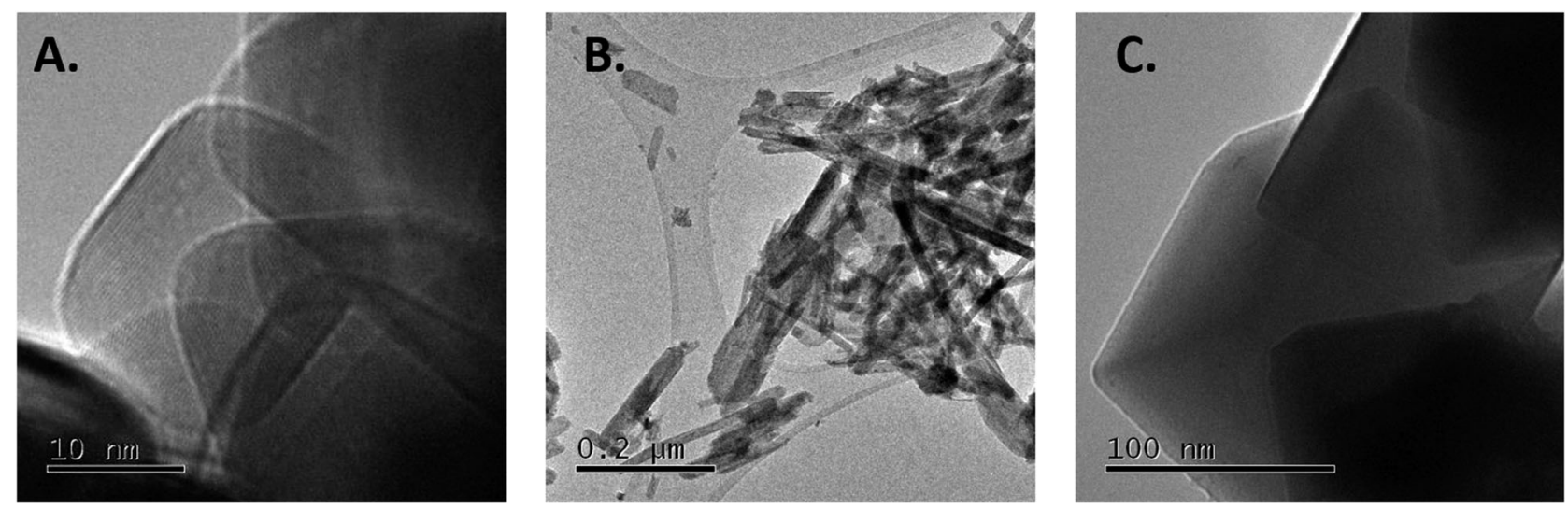

Fig. 1 TEM pictures of the (A) 20 wt\% Fe/ceria nanoparticles, (B) 20 wt\% Fe/ceria nanorods and (C) 20 wt\% Fe/ceria nanocubes. 


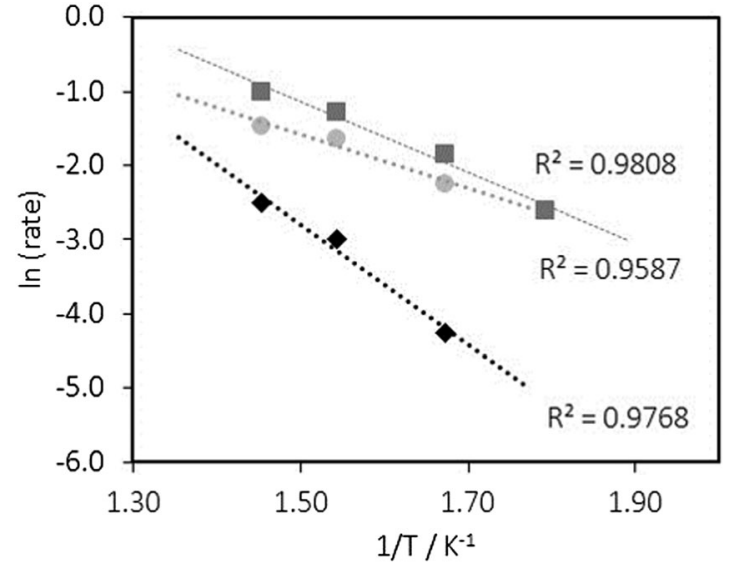

Fig. 2 Arrhenius plot for the $\mathrm{CO}_{2}$ hydrogenation reaction with $20 \mathrm{wt} \%$ $\mathrm{Fe} / \mathrm{CeO}_{2}$ particles $20 \mathrm{wt} \% \mathrm{Fe} / \mathrm{CeO}_{2}$ rods $20 \mathrm{wt} \% \mathrm{Fe} / \mathrm{CeO}_{2}$ cubes. Rate values are expressed as mol $\mathrm{HC}$ formed $\mathrm{mol}_{\mathrm{Fe}}{ }^{-1} \mathrm{~h}^{-1}$

than that of the Fe/ceria rods (44.6 $\mathrm{kJ} \mathrm{mol}^{-1}$ ) (Fig. 2). On the other hand, Fe/ceria particles present a high activation energy $\left(67.3 \mathrm{~kJ} \mathrm{~mol}^{-1}\right)$ with only formation of $\mathrm{C}_{1}-\mathrm{C}_{2}$ hydrocarbons suggesting that the growth-chain probability is greatly limited in this system.

The XRD spectra of the different $\mathrm{Fe} / \mathrm{CeO}_{2}$ catalysts show the crystalline structure of the support with diffraction patterns corresponding to the pure cubic phase (ceria fluorite structure, JCPDS 34-0394). ${ }^{25}$ Additionally, diffraction peaks at $2 \theta$ angles of $35.5^{\circ}$ and $62.5^{\circ}$ corresponding to the (110) and (214) planes of the $\mathrm{Fe}_{2} \mathrm{O}_{3}$ are also present. The former peak is used to calculate the $\mathrm{Fe}_{2} \mathrm{O}_{3}$ crystallite size using the Scherrer's equation showing a similar average iron size $(\sim 30 \mathrm{~nm})$ when ceria rods and cubes are used as support. On the contrary, an iron average size of $\sim 73 \mathrm{~nm}$ is present on the catalysts supported on ceria particles. The similarity of the iron species sizes in the rods and the cubes catalysts and the difference in reactivity reveals the intrinsic effect of the morphology of the ceria support. In general, the olefin/paraffin ratio increases as the reaction temperature increases, however, olefin formation is greatly promoted when ceria particles and cubes are used as support in comparison to the ceria rods counterparts. Ceria rods are known to selectively expose the (110) and (100) surface planes, presenting a higher surface oxygen concentration and higher reducibility at lower temperatures than the ceria particles enclosing (111) and (100) facets and the ceria cubes with exposed (100) planes. $^{25}$ Indeed, the ceria reducibility decreases in the order rods $>$ particles $>$ cubes, following the same trend that the olefin/paraffin ratio suggesting that the ceria support can play a key role on the saturation of the HC products, especially in the catalyst supported on the ceria rods. Although the catalysts are reduced at $400{ }^{\circ} \mathrm{C}$ prior the reaction, the support can also have an effect on the actual iron species formed under reaction conditions ${ }^{5}$ and the reduction degree of the iron due to the different concentration of surface oxygen species in the support. The temperature programme reduction of the different nanostructured ceria supports are shown in Fig. 3, in addition to their corresponding Fe/ceria counterparts. The bare ceria nanoparticles and nanorods present a reduction

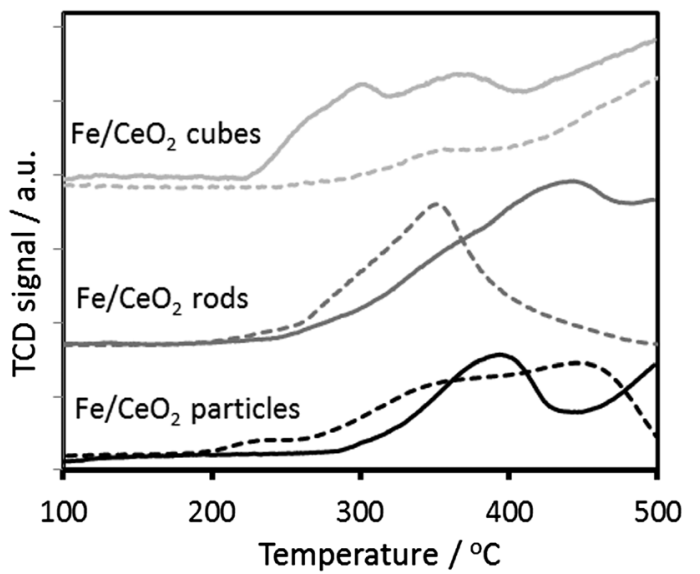

Fig. 3 Temperature programme reduction of the different 20 wt\% Fe/ ceria catalysts (solid line) and their corresponding ceria support (dashed line). Data is normalised per mass of catalyst.

peak starting at $\sim 250{ }^{\circ} \mathrm{C}$ related to the reduction of readily reduced ceria oxygen (in some cases also called surface oxygen) while the extension of this peak in the ceria nanocubes is comparably smaller. Indeed, we have recently shown that only $10 \%$ of the oxygen available in the ceria nanocubes is readily reducible oxygen compared to the $35-45 \%$ in the ceria nanoparticles and nanorods. ${ }^{26}$ Desaunay et al. $^{31}$ have recently shown the contribution of the different crystal plane exposure to the low temperature reduction peak, formed by inter-convoluted peaks.

The presence of iron, increases the reduction temperature in the catalysts supported on the ceria particles and rods in respect to the corresponding ceria support, suggesting a high metal-support interaction. Contrary, it appears that the $\mathrm{Fe} / \mathrm{CeO}_{2}$ cubes catalyst partially reduces at lower temperatures $\left(<300{ }^{\circ} \mathrm{C}\right)$ than the particles and rods counterparts. Interestingly, the initial reduction temperature of the $\mathrm{Fe} /$ ceria catalysts is directly related to the olefin/paraffin ratio observed in this system.

The addition of platinum in $\mathrm{F}-\mathrm{T}$ catalysts has been demonstrated to facilitate the reduction of the active species, especially in cobalt-based catalysts. ${ }^{32}$ In order to further facilitate the formation of the iron active species on the $\mathrm{Fe} / \mathrm{CeO}_{2}$ catalysts, the $\mathrm{Fe} / \mathrm{CeO}_{2}$ rods and the $\mathrm{Fe} / \mathrm{CeO}_{2}$ cubes catalysts were physically mixed with ( $1 \mathrm{wt} \%) \mathrm{Pt} / \mathrm{CeO}_{2}$ rods and $\mathrm{Pt} / \mathrm{CeO}_{2}$ cubes respectively. The $\mathrm{CO}_{2}$ conversion greatly increases, Table 2 , in the case of the ceria rod catalysts due to the high reactivity of the platinum species in the RWGS reaction under these conditions. ${ }^{24}$ However, the mixture of $\mathrm{Fe} / \mathrm{CeO}_{2}$ and $\mathrm{Pt} / \mathrm{CeO}_{2}$ rods catalysts produce only methane and $\mathrm{CO}$ as products (Table 2). In the case of the physical mixture of iron and platinum catalysts supported on ceria cubes, no obvious effect of the presence of platinum on the $\mathrm{CO}_{2}$ conversion or HC selectivity is observed compared to the only-Fe catalyst. However, the ability of platinum particles to spill-over hydrogen on the ceria surface ${ }^{33}$ greatly promotes the saturation of the HC products, leading to very low olefin/paraffin ratios. Additionally, when iron and platinum are co-impregnated on ceria cubes (Table 2), the $\mathrm{CO}_{2}$ conversion and selectivity to $\mathrm{HC}$ are slightly lower than in the iron-only catalyst.

However, the methane selectivity versus longer $\mathrm{HC}$ is considerable lower in the presence of co-impregnated platinum. Although the 
Table 2 Catalytic performance of 20 wt\% Fe-1 wt\% Pt supported on nanostructured ceria for the hydrogenation of $\mathrm{CO}_{2}$

\begin{tabular}{|c|c|c|c|c|c|c|c|c|c|c|}
\hline \multirow[b]{2}{*}{ Catalyst } & \multirow{2}{*}{$\begin{array}{l}\text { Reaction } \\
\text { temperature } /{ }^{\circ} \mathrm{C}\end{array}$} & \multirow{2}{*}{$\begin{array}{l}\mathrm{CO}_{2} \\
\text { conversion/\% }\end{array}$} & \multirow{2}{*}{$\begin{array}{l}\text { Selectivity } \\
\mathrm{CO} / \%\end{array}$} & \multirow{2}{*}{$\begin{array}{l}\text { Selectivity to } \\
\mathrm{HCs} / \%\end{array}$} & \multicolumn{5}{|c|}{ Hydrocarbon selectivity/\% } & \multirow{2}{*}{$\begin{array}{l}\text { Olefin/paraffin } \\
\text { ratio }\end{array}$} \\
\hline & & & & & $\mathrm{CH}_{4}$ & $\mathrm{C} 2-4=$ & $\mathrm{C} 2-4$ & $\mathrm{C} 5+=$ & C5+ & \\
\hline $20 \mathrm{wt} \% \mathrm{Fe} / \mathrm{CeO}_{2}$ rods $+1 \mathrm{wt} \%$ & 260 & 16.9 & 92.3 & 7.69 & 75.0 & 0.0 & 21.7 & 0.0 & 1.4 & 0.00 \\
\hline cencos & 350 & 32 & 75.39 & 24.7 & 93.8 & 0.0 & 6.1 & 0.0 & 0.0 & 0.00 \\
\hline & 390 & 48.6 & 61.9 & 38.1 & 99.4 & 0.0 & 0.6 & 0.0 & 0.0 & 0.00 \\
\hline \multirow{2}{*}{$\begin{array}{l}20 \mathrm{wt} \% \mathrm{Fe} / \mathrm{CeO}_{2} \text { cubes }+1 \mathrm{wt} \% \\
\mathrm{Pt} / \mathrm{CeO}_{2} \text { cubes (physical mix) }\end{array}$} & 260 & 5.3 & 90.6 & 9.4 & 68.7 & 1.6 & 24.5 & 0.0 & 2.3 & 0.06 \\
\hline & 390 & 15.2 & 73.0 & 27.0 & 78.6 & 0.6 & 19.7 & 0.0 & 1.0 & 0.03 \\
\hline \multirow{4}{*}{$\begin{array}{l}20 \mathrm{wt} \% \mathrm{Fe} / \mathrm{CeO}_{2} \text { cubes }+1 \mathrm{wt} \% \\
\mathrm{Pt} / \mathrm{CeO}_{2} \text { cubes (co-impregnation) }\end{array}$} & 260 & 6.7 & 94.3 & 5.7 & 66.2 & 10.7 & 23.1 & 0.0 & 0.0 & 0.47 \\
\hline & 300 & 5.5 & 70.9 & 29.1 & 57.5 & 11.1 & 26.0 & 1.2 & 1.2 & 0.45 \\
\hline & 350 & 11.9 & 79.0 & 21.0 & 53.5 & 12.5 & 30.4 & 0.1 & 1.6 & 0.39 \\
\hline & 390 & 16.3 & 85.9 & 14.1 & 62.2 & 7.3 & 29.0 & 0.4 & 1.1 & 0.25 \\
\hline
\end{tabular}

Reaction conditions: $0.3 \mathrm{~g}$ of each catalysts (total of $0.6 \mathrm{~g}$ when physical mixtures are used) pre-reduced at $400{ }^{\circ} \mathrm{C}$ under $50 \mathrm{~mL} \mathrm{~min}{ }^{-1} \mathrm{H}_{2}$ flow. Inlet gas: $8 \mathrm{~mL} \mathrm{~min}{ }^{-1}$ of $3: 1 \mathrm{H}_{2} / \mathrm{CO}_{2}$ ratio. GHSV: $200 \mathrm{~h}^{-1}$. The experimental error associated to the analysis is $<4 \%$.

olefin/paraffin ratio is higher in the co-impregnated catalysts than with a physical mixture of $\mathrm{Fe}$ and $\mathrm{Pt}$ ceria, the ratio is significantly lower than in the only-Fe/ $\mathrm{CeO}_{2}$ cubes catalysts, demonstrating than promotion of hydrogen spill-over can minimize the previously discussed effect of the support in the selectivity. ${ }^{34}$

In conclusion, this study demonstrates that the morphology of the ceria support on $\mathrm{Fe} / \mathrm{CeO}_{2}$ catalyst plays a key role not only on the $\mathrm{CO}_{2}$ conversion but also on the methane to hydrocarbon selectivity and the olefin to paraffin ratio. Iron supported on nanostructured ceria rods presents the highest hydrocarbon selectively versus $\mathrm{CO}$ formation however higher olefin/paraffin ratios are achieved with ceria cubes as support. This modification of the iron reactivity is related to the high metal-support interaction shown by the shift of the reduction temperatures of the $\mathrm{Fe} / \mathrm{CeO}_{2}$ catalysts in respect to their corresponding supports, associated to the selective exposure of different crystal planes in the different ceria morphologies. Addition of either platinum/ceria catalysts or co-impregnation with iron, greatly promotes the saturation of the products masking the effect of the support.

The authors thanks the UK Engineering and Physical Science Research Council (EPSRC, grant numbers: EP/L020432/2 and $\mathrm{EP} / \mathrm{G} 03768 \mathrm{X} / 1)$.

\section{Notes and references}

$\dagger$ Nanostructured ceria was synthesised by an alkali hydrothermal method using an un-stirred acid digestion bomb equipped with a PTFE liner using the conditions described in the text. Further details can be found elsewhere. ${ }^{25}$ Iron and platinum was supported on the different supports via incipient wetness impregnation using $\mathrm{Fe}\left(\mathrm{NO}_{3}\right)_{3} \cdot 9 \mathrm{H}_{2} \mathrm{O}$ and $\mathrm{H}_{2} \mathrm{PtCl}_{6}$ as iron and platinum precursors respectively. X-ray diffraction (XRD) characterisation was carried out using an X'Pert PRO diffractometer by PANalytical with a $\mathrm{Cu} K \alpha$ radiation and the crystalline phases were identified by matching the experimental patterns to the JCPDS powder diffraction file database. Temperature programmed reductions (TPR) were carried out under a $50 \mathrm{~mL} \mathrm{~min}^{-1} 5 \% \mathrm{H}_{2} / \mathrm{Ar}$ flow from room temperature to $500{ }^{\circ} \mathrm{C}$ with a heating rate of $10{ }^{\circ} \mathrm{C} \mathrm{min}{ }^{-1}$. The activity of the catalysts in the direct $\mathrm{CO}_{2}$ hydrogenation reactions was measured using a differential packed bed reactor where the catalysts were in situ pre-reduced at $400{ }^{\circ} \mathrm{C}$ under $50 \mathrm{~mL} \mathrm{~min}{ }^{-1} \mathrm{H}_{2}$ flow. In a typical experiment, $0.3 \mathrm{~g}$ of the catalyst was diluted in $\mathrm{SiC}$ up to a $2.5 \mathrm{~cm}^{3}$ catalytic bed. The test were carried out at atmospheric temperature using $8 \mathrm{~mL} \mathrm{~min}{ }^{-1} \mathrm{H}_{2}$ / $\mathrm{CO}_{2}$ feed with $3: 1$ volumetric ratio. The outlet gas was analysed by gas chromatography (Agilent 7890A) fitted with a FID, TCD and a Mass Spec. The experimental error associated to the analysis is $<4 \%$.

1 G. Centi, E. A. Quadrelli and S. Perathoner, Energy Environ. Sci., 2013, 6, 1711-1731.

2 M. Aresta and A. Dibenedetto, Dalton Trans., 2007, 2975-2992.

3 V. White, L. Torrente-Murciano, D. Sturgeon and D. Chadwick, Int. J. Greenhouse Gas Control, 2010, 4, 137-142.

4 L. Torrente-Murciano, V. White, F. Petrocelli and D. Chadwick, Energy Procedia, 2011, 4, 908-916.

5 W. Wang, S. P. Wang, X. B. Ma and J. L. Gong, Chem. Soc. Rev., 2011, 40, 3703-3727.

6 M. Cokoja, C. Bruckmeier, B. Rieger, W. A. Herrmann and F. E. Kuhn, Angew. Chem., Int. Ed., 2011, 50, 8510-8537.

7 K. Fujimoto and T. Shikada, Appl. Catal., 1987, 31, 13-23.

8 J. F. Lee, W. S. Chern, M. D. Lee and T. Y. Dong, Can. J. Chem. Eng., 1992, 70, 511-515.

9 G. Centi and S. Perathoner, Catal. Today, 2009, 148, 191-205. 10 L. Torrente-Murciano, D. Mattia, M. D. Jones and P. K. Plucinski, J. CO2 Util., 2014, 6, 34-39.

11 G. P. Van der Laan and A. Beenackers, Catal. Rev.: Sci. Eng., 1999, 41, 255-318.

12 R. W. Dorner, D. R. Hardy, F. W. Williams, B. H. Davis and H. D. Willauer, Energy Fuels, 2009, 23, 4190-4195.

13 Y. Q. Zhang, G. Jacobs, D. E. Sparks, M. E. Dry and B. H. Davis, Catal. Today, 2002, 71, 411-418.

14 T. Riedel, M. Claeys, H. Schulz, G. Schaub, S. S. Nam, K. W. Jun, M. J. Choi, G. Kishan and K. W. Lee, Appl. Catal., A, 1999, 186, 201-213.

15 M. E. Dry, Appl. Catal., A, 1996, 138, 319-344.

16 J. A. Rodriguez, J. Evans, L. Feria, A. B. Vidal, P. Liu, K. Nakamura and F. Illas, J. Catal., 2013, 307, 162-169.

17 W. Chen, Z. L. Fan, X. L. Pan and X. H. Bao, J. Am. Chem. Soc., 2008, 130, 9414-9419.

18 E. de Smit, F. Cinquini, A. M. Beale, O. V. Safonova, W. van Beek, P. Sautet and B. M. Weckhuysen, J. Am. Chem. Soc., 2010, 132, 14928-14941. 
19 D. R. Minett, J. P. O’Byrne, S. I. Pascu, P. K. Plucinski, R. E. Owen, M. D. Jones and D. Mattia, Catal. Sci. Technol., 2014, 4, 3351-3358.

20 J. J. Wang, Z. Y. You, Q. H. Zhang, W. P. Deng and Y. Wang, Catal. Today, 2013, 215, 186-193.

21 M. L. Cubeiro, H. Morales, M. R. Goldwasser, M. J. PerezZurita and F. Gonzalez-Jimenez, React. Kinet. Catal. Lett., 2000, 69, 259-264.

22 R. W. Dorner, D. R. Hardy, F. W. Williams and H. D. Willauer, Appl. Catal., A, 2010, 373, 112-121.

23 L. Y. Xu, Q. X. Wang, D. B. Liang, X. Wang, L. W. Lin, W. Cui and Y. D. Xu, Appl. Catal., A, 1998, 173, 19-25.

24 L. Torrente-Murciano and F. R. Garcia-Garcia, Catal. Commun., 2015, 71, 1-6.

25 L. Torrente-Murciano, A. Gilbank, B. Puertolas, T. Garcia, B. Solsona and D. Chadwick, Appl. Catal., B, 2013, 132-133, 116-122.

26 J. M. López, A. L. Gilbank, T. García, B. Solsona, S. Agouram and L. Torrente-Murciano, Appl. Catal., B, 2015, 174-175, 403-412.
27 G. N. Vayssilov, Y. Lykhach, A. Migani, T. Staudt, G. P. Petrova, N. Tsud, T. Skala, A. Bruix, F. Illas, K. C. Prince, V. Matolin, K. M. Neyman and J. Libuda, Nat. Mater., 2011, 10, 310-315.

28 S. Carrettin, P. Concepcion, A. Corma, J. M. L. Nieto and V. F. Puntes, Angew. Chem., Int. Ed., 2004, 43, 2538-2540.

29 E. de Smit and B. M. Weckhuysen, Chem. Soc. Rev., 2008, 37, 2758-2781.

30 J. C. Medina, S. J. Butala, C. H. Bartholomew and M. L. Lee, Fuel, 2000, 79, 89-93.

31 T. Desaunay, G. Bonura, V. Chiodo, S. Freni, J. P. Couzinie, J. Bourgon, A. Ringuede, F. Labat, C. Adamo and M. Cassir, J. Catal., 2013, 297, 193-201.

32 S. Vada, A. Hoff, E. Adnanes, D. Schanke and A. Holmen, Top. Catal., 1995, 2, 155-162.

33 I. Ivanov, P. Petrova, V. Georgiev, T. Batakliev, Y. Karakirova, V. Serga, L. Kulikova, A. Eliyas and S. Rakovsky, Catal. Lett., 2013, 143, 942-949.

34 J. P. O’Byrne, R. E. Owen, D. R. Minett, S. I. Pascu, P. K. Plucinski, M. D. Jones and D. Mattia, Catal. Sci. Technol., 2013, 3, 1202-1207. 